\title{
Preservation in Paraffin Oil: Alternative for Fungi Preservation in Simple Laboratory Concept
}

\author{
Sem Samuel Surja, ${ }^{1}$ Gabi Vania Sally, ${ }^{2}$ Favian Sergius Ruby Hartoyo, ${ }^{2}$ \\ Sandy Vitria Kurniawan, ${ }^{3}$ Yanto Budiman ${ }^{4}$ \\ ${ }^{1}$ Department of Parasitology School of Medicine and Health Sciences Universitas Katolik \\ Indonesia Atma Jaya Jakarta, Indonesia, ${ }^{2}$ School of Medicine and Health Sciences Universitas \\ Katolik Indonesia Atma Jaya Jakarta, Indonesia, ${ }^{3}$ Department of Pharmacology School of \\ Medicine and Health Sciences Universitas Katolik Indonesia Atma Jaya Jakarta, Indonesia, \\ ${ }^{4}$ Department of Radiology School of Medicine and Health Sciences Universitas Katolik Indonesia \\ Atma Jaya Jakarta, Indonesia
}

\section{Abstract}

Background: A good collection of fungi culture can be maintained with good preservation methods. With appropriate methods, preservation can be performed in low-budget laboratories, such as with periodic subculture and preservation in either sterile water or in paraffin oil. The aim of this study was to assess the viability, morphology, contamination, and antifungal susceptibility profile of fungi preserved in sterile water or paraffin oil compared to a periodic subculture.

Methods: This study was an experimental study using Aspergillus sp., Trichophyton mentagrophytes and Candida albicans conducted in the Parasitology Laboratory, School of Medicine and Health Sciences, Universitas Katolik Indonesia Atma Jaya, Jakarta from March to October 2019. The fungi were preserved by a periodic subculture or in sterile water or in paraffin oil for six months. A comparison of viability, morphology, contamination, and antifungal susceptibility profile between methods were made before and after six months of study.

Results: The viability of all the fungi was maintained in both periodic subculture and preservation with paraffin oil. However, the T. mentagrophytes was not viable in preservation using sterile water. All methods could maintain the morphology without contamination. There were reductions in the inhibition zone against antifungal drug in preservation with sterile water and paraffin oil.

Conclusions: Preservation in paraffin oil is superior to preservation in sterile water in terms of maintaining fungal viability. This method is suitable for the use in a simple laboratory, albeit considerations should be given to the reduction of inhibition zone.

Keywords: Fungi, paraffin oil, preservation, sterile water

\section{Introduction}

There are over 1.5 million various fungi strains in the world and only 100.000 strains are already identified. The identifying process of a fungus takes a long time, therefore, culture collection is importantto maintain strains of the fungus viable before it can later be identified. ${ }^{1}$ Medically or biotechnologically important fungi are considered paramount to preserve because of their unique properties and practical value in various aspects of human life. ${ }^{2,3}$ These strains are important for producing enzymes, proteins, vitamins, bioactive compounds, antimicrobial substances, and biopolymers. Its application in the medical aspect could be in the field of diagnostic or development of new therapeutics. ${ }^{3}$

A good culture collection needs a good preservation method that can preserve a fungus for a long time. There are many methods of fungi preservation techniques, such as periodic subculture, freeze-drying preservation technique, preservation in sterile water or paraffin oil, and many more. Periodic subculture is the easiest way to preserve fungi for a short period, however, it has some disadvantages such as the inability to ensure

Correspondence: Sem Samuel Surja, Department of Parasitology, School of Medicine and Health Sciences Universitas Katolik Indonesia Atma Jaya Jakarta, Jl. Pluit Raya No. 2, Penjaringan, Jakarta Utara, Indonesia, E-mail: sem.samuel@atmajaya.ac.id 

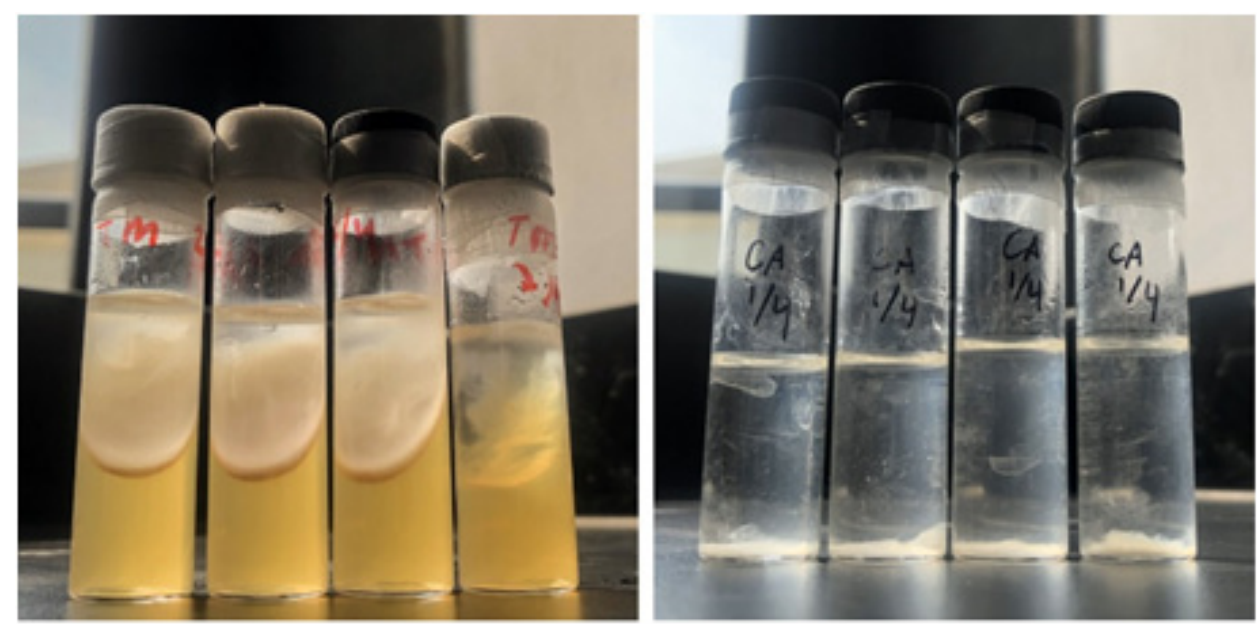

Figure 1 Preservation in Paraffin Oil (Left) and Sterile Water (Right)

fungus viability for a long preservation period and potential of human errors in labeling. Currently, the freeze-drying preservation technique is the method of choice for long-term fungal preservation. Its major drawback is it requires advance high-technology equipment, thus, it cannot be performed in a simple laboratory. ${ }^{4}$

Alternatively, most educational or research institutes prefer using periodic subcultures in preserving their fungi due to the higher cost of previous technique Studies have shown that preservation in sterile water or paraffin oil could be used to preserve a wider range of fungi. These traditional methods could maintain the long-term viability of the fungi and only require basic microbiology laboratory skills and equipment. Therefore, these twopreservation methods could be done in a simple laboratory. ${ }^{5-8}$

With an increasing number of antifungal resistances of many unusual and rare fungi, studies examining the susceptibility profile of fungi are now widely conducted. Most of the source of the fungi is culture collection since strains should be collected over years to reach an amount sufficient to be studied. ${ }^{9}$ As for culture collection, many studies included viability and contamination as parameters in preservation technique research, but the alteration of antifungal susceptibility has been never examined. Assessment of this parameter is important since alteration caused by preservation technique could cause misinterpretation of antifungal susceptibility results and potentially mislead treatment strategy.

This study aimed to assess the viability, morphology, contamination, and antifungal susceptibility profile of fungi preserved with sterile water or paraffin oil. Aspergillus $s p$. and Trichophyton mentagrophytes were used to represent fast-growing and slow-growing molds and Candida albicans to represent yeast. The result of this study was to be applied in a simple laboratory.

\section{Methods}

This experimental study was conducted in the Parasitology Laboratory, School of Medicine and Health Sciences, Universitas Katolik Indonesia Atma Jaya, Jakarta from March to October 2019. Aspergillus sp., T. mentagrophytes, and C.albicans were obtained from the culture collection of the Laboratory. All cultures were initially grown in sabouraud dextrose agar (SDA, Oxoid, United Kingdom).

The preservation techniques used were periodic subculture and preservation in sterile water or paraffin oil (Figure 1). The periodic subculture method was performed by simply transferring fungi into a new SDA once every two months. ${ }^{10}$ Preservation with sterile water was conducted initially by flooding cultured fungi with 6-7 ml sterile water. The culture was scrapped lightly using pipette tips. The suspension was withdrawn and transferred to the McCartney tube. ${ }^{11}$ As for preservation in paraffin oil, fungi were first inoculated onto slant of SDA inside the McCartney tubes. Cultured fungi were then flooded with autoclaved paraffin oil until $1 \mathrm{~cm}$ above the culture. ${ }^{4,8}$ All fungi were preserved using these three methods for six months at room temperature. 
Table 1 Viability, Morphology, and Contamination of Aspergillus sp., Trichophyton mentagrophytes, and Candida albicans Before and After Preservation

\begin{tabular}{|c|c|c|c|c|c|}
\hline \multirow[b]{2}{*}{ Parameters } & \multirow[b]{2}{*}{ Fungi } & \multirow{2}{*}{$\begin{array}{c}\text { Before } \\
\text { preservation }\end{array}$} & \multicolumn{3}{|c|}{ After six months } \\
\hline & & & $\begin{array}{c}\text { Periodic } \\
\text { Subculture }\end{array}$ & Sterile Water & Paraffin Oil \\
\hline \multirow[t]{3}{*}{ Viability } & Aspergillus sp. & + & + & + & + \\
\hline & $\begin{array}{l}\text { Trichophyton } \\
\text { mentagrophytes }\end{array}$ & + & + & - & + \\
\hline & Candida albicans & + & + & + & + \\
\hline \multirow[t]{3}{*}{ Morphology } & Aspergillus sp. & + & + & + & + \\
\hline & $\begin{array}{l}\text { Trichophyto } n \\
\text { mentagrophytes }\end{array}$ & + & + & - & + \\
\hline & Candida albicans & + & + & + & + \\
\hline \multirow[t]{3}{*}{ Contamination } & Aspergillus sp. & - & - & - & - \\
\hline & $\begin{array}{l}\text { Trichophyto } n \\
\text { mentagrophytes }\end{array}$ & - & - & + & - \\
\hline & Candida albicans & - & - & - & - \\
\hline
\end{tabular}

Note: Viable fungus was markedas (+). Morphology was marked as (+) if fungi showed typical morphology of the species. Contamination was marked as $(+)$ if it occured

Before preservation, fungi were tested for its viability, microscopic morphology, and antifungal susceptibility. The rice cream test was used for yeast (C. albicans) and the slide culture technique was used for molds (Aspergillus sp. and T. mentagrophytes). ${ }^{12,13}$ Morphology were checked based on its characteristic. ${ }^{14}$ Antifungal susceptibility was examined using the disk diffusion technique according to CLSI M51-A for Aspergillus sp. and T. mentagrophytes and CLSI M60 for C. albicans. ${ }^{13-15}$ It was measured using an average the zone of inhibition against voriconazole disk for Aspergillus sp., itraconazole disk for T. mentagrophytes, and fluconazole disk for $C$. albicans. All assessments were conducted in two times of repetition.

After being preserved for six months, the preserved cultures were reassessed for its viability, microscopic morphology, antifungal susceptibility, and level of contamination. The revival of fungi preserved in sterile water was conducted by inoculating $0.2-0.3 \mathrm{ml}$ of the suspension with a sterile pipette to SDA. ${ }^{11}$ For the revival of fungi preserved in paraffin oil, preserved fungi were swabbed and transferred into SDA.

Additionally, every two months preserved cultures were checked for its viability by transferring preserved cultures in a new medium. This study was approved by the Ethical Committee, School of Medicine and Health Sciences Atma Jaya Catholic University of Indonesia No:06/05/KEP-FKUAJ/2019 and No: 13/06/KEP-FKUAJ/2019.

\section{Results}

Periodic subculture and preservation in paraffin oil could maintain the viability of Aspergillus sp., T. mentagrophytes, and $C$. albicans, while preservation in sterile water could maintain the viability of Aspergillus $s p$. and C. albicans but not T.mentagrophytes (Table 1). Candida albicans preserved in paraffin oil showed slower growing time (5-7 days) than periodic subculture and in sterile water (24-48 hours). Aspergillus sp. grew after 3-4 days for periodic subculture and paraffin oil, and 4 days for sterile water. T. mentagrophytes' growing time was 5-7 days for periodic subculture and paraffin oil.

In all viable fungi, microscopic morphology was not changed. C. albicans showed the marked formation of blastospore, pseudohyphae, and chlamydospore in the rice cream test, Aspergillus sp. Showed uniseriatephialides on the conidial head, and T. mentagrophytes showed some hyphae that were spiralshaped with spores arranged in the group. Contaminations were not shown in any fungi except $T$. mentagrophytes preservation with sterile water. Results of microscopic morphology and contamination were summarized in Table 1.

When tested by using the disk diffusion test, there was a reduction in the zone of inhibition for preservation in paraffin oil. The zone of inhibition for $C$. albicans showed the highest reduction from $34 \mathrm{~mm}$ to $25 \mathrm{~mm}$ after preservation in paraffin oil. Both Aspergillus sp. 
Table 2 Antifungal Susceptibility (Zone of Inhibition) of Aspergillus sp., Trichophyton mentagrophytes, and Candida albicans Before and After Preservation

\begin{tabular}{|c|c|c|c|c|c|c|c|c|c|}
\hline \multirow{3}{*}{$\begin{array}{l}\text { Parameters } \\
\text { Antifungal } \\
\text { Susceptibility }\end{array}$} & \multirow{3}{*}{$\begin{array}{c}\text { Fungi } \\
\text { Aspergillus sp. }\end{array}$} & \multirow{2}{*}{\multicolumn{2}{|c|}{$\begin{array}{c}\text { Before } \\
\text { preservation } \\
(\mathrm{mm})\end{array}$}} & \multicolumn{6}{|c|}{ After six months } \\
\hline & & & & \multicolumn{2}{|c|}{$\begin{array}{c}\text { Periodic } \\
\text { Subculture }\end{array}$} & \multicolumn{2}{|c|}{ Sterile Water } & \multicolumn{2}{|c|}{ Paraffin 0il } \\
\hline & & 35 & 34 & 32 & 30 & 30 & 31 & 25 & 25 \\
\hline & $\begin{array}{l}\text { Trichophyton } \\
\text { mentagrophytes }\end{array}$ & 45 & 40 & 45 & 45 & - & - & 36 & 38 \\
\hline & Candida albicans & 32 & 34 & 33 & 32 & 34 & 35 & 25 & 24 \\
\hline
\end{tabular}

Note: Zone of inhibition was expressed in millimeter (mm)

and T. mentagrophytes preserved in paraffin oil, reduction in the zone of inhibition were around $7 \mathrm{~mm}$. For the periodic subculture method and preservation in sterile water, there was the only a low reduction in the zone of inhibition. Results of the antifungal susceptibility profile were summarized in Table 2.

\section{Discussion}

Preservation in paraffin oil could maintain the viability of Aspergillus sp., Trichophyton mentagrophytes, and C. albicans. Moreover, paraffin oil could maintain microscopic morphology before and after preservation with no contamination. This is in accordance with a study by Smith D et al. ${ }^{7}$ which preserved 58 strains of fungi and 47 strains that were still viable after being stored for 20 years in paraffin oil. Similarly, Ajello et al. ${ }^{6}$ also preserved 34 strains of fungi in paraffin oil and all strains that were still viable after being stored for 19-21 months.

Preservation in sterile water could maintain the viability of Aspergillus sp. and C. albicans. Similar studies by McGinnis MR et al. ${ }^{11}$ showed Aspergillus sp. could still viable until 12 months and $C$. albicans until 60 months with no contamination after preservation in sterile water. Moreover, Suciatmih S et al. ${ }^{5}$ conducted a preservation study with sterile water and resulted in a $100 \%$ survival rate, and de Caprilles $\mathrm{CH}$ et al. ${ }^{16}$ conducted a preservation study for 20 years and the survival rate around $50 \%$ with $22.8 \%$ contamination. In our study, T. mentagrophytes (dermatophyte) did not survive after being preserved in sterile water. Some studies had reported that dermatophytes were more difficult to preserve in the long term using sterile water for example Karabıçak N et al. ${ }^{17}$ reported that 3\% of 1186 samples did not survive in sterile water after
12 years and all were dermatophytes. These studies along with our study have shown that preservation in sterile water could be used for shorter preservation time (around five years) than paraffin oil. This method is not preferred for dermatophyte and maybe also for another slow-growing fungus.

In the antifungal susceptibility test, there was a reduction in the zone of inhibition against the antifungal drugs, which could be interpreted as an increase of resistance in the fungi. The reason for the reduction in the zone of inhibition at the disk diffusion test is unclear. A study assessing this issue after the preservation method is lacking. We assume increased resistance against antifungal has something to do with materials used in preservation. The adaptation process can change how fungi react to certain conditions. Fungi in nutrient-limited conditions somehow become adapted in that harsh condition and maximizing its capability to survive. Autophagy is an important response when cells are starving, to maintain viability in a state of malnutrition. It refers to a group of processes that involves the degradation of cytoplasmic components. ${ }^{18}$ Autophagy in mold and yeast could function as a nutrient recycling pathway that supports survival in growth that occurs under nutrient-limited conditions. ${ }^{18,19}$ We believe this mechanism increases the resistance of the fungi against the antifungal drugs. When fungi in both preservation methods were revived and further subcultured in a nutrient-rich medium, the susceptibility profile might be gradually increased to its original pattern.

There was an elongation of C. albicans growth. In general, $C$. albicans growth was visible after 24-48 hours. Inoculum of $C$. albicans from preservation in paraffin oil grew in a slower time (5-7 days). This phenomenon 
could be explained by the ability of paraffin oil to inhibit oxygen ingress into the culture, so the metabolism of the fungi was suppressed. Inhibited metabolism will further inhibit the sporulation of the fungi. ${ }^{6,20}$ There could be a slight elongation in the growing time of the fungus for the first revival. When the culture was transferred into a new medium for the second time, fungi would regain its growth rate to normal. ${ }^{7}$

This study has potential limitations. Preservation was only performed for six months. Longer preservation time should be performed to further observe the potential of these preservation techniques. Given the limited fungi used in this study, more species and strain are needed for further study. Also, these preservation techniques need some additional examination to prove its capability on maintaining genotypic and phenotypic stability of the culture. The molecular method should be performed for such purpose.

In conclusion, preservation in paraffin oil maintain viability, microscopic morphology, as well as preventing contamination of preserved fungi. Assessment of antifungal susceptibility profile using preserved fungi in paraffin oil should consider the increased resistance at a first revival after preservation. Further subculture might be needed for this purpose. Preservation in paraffin oil is superior to sterile water and this technique is encouraged to be used in a simple laboratory.

\section{References}

1. Smith D. Culture collections over the world. Int Microbiol. 2003;6(2):95-100.

2. Prakash 0, NimonkarY, Shouche YS. Practice and prospects of microbial preservation. FEMS Microbiol Lett. 2013;339(1):1-9.

3. Sievers M. Culture collections in the study of microbial diversity, importance. In: Nelson $\mathrm{KE}$, editor. Encyclopedia of metagenomics. Boston: MA Springer; 2015. p. 111-114.

4. Machmud M. Teknik penyimpanan dan pemeliharaan mikroba. Bul AgroBio. 2001;4(1):24-32.

5. Suciatmih S, Rachmat R. Pengujian survival jamur yang dipreservasi dalam air dan parafin cair [Survival testing of preserved fungi in water and liquid-paraffin ]. Berita Biologi. 2005;7(5):241-8.

6. Ajello L, Grant VQ Gutzke MA. Use of mineral oil in the maintenance of cultures of fungi pathogenic for humans. AMA Arch Derm Syphilol. 1951;63(6):747-9.

7. Smith D, Onions AHS. A comparison of some preservation techniques for fungi. Trans Br Mycol Soc. 1983;81(3):535-40.

8. Buell CB, Weston WH. Application of the mineral oil conservation method to maintaining collections of fungous cultures. Am J Bot. 1947;34(10):555-61.

9. Surja SS, Adawiyah R, Houbraken J, Rozaliyani A, Sjam R, Yunihastuti E, et al. Talaromyces atroroseus in HIV and nonHIV patient: A first report from Indonesia. Med Mycol. 2020;58(4):560-63

10. James C, Welsh C. Microbiology: A laboratory manual. $11^{\text {th }}$ ed. England: Pearson Education; 2017

11. Mcginnis MR, PadhyeAA, Ajello L. Storage of stock cultures of filamentous fungi,yeasts, and some aerobic actinomycetes in sterile distilled water. Appl Microbiol. 1974;28(2):218-22.

12. Rosana Y, Matsuzawa T, Gonoi T, Karuniawati A. Modified slide culture method for faster and easier identification of dermatophytes. Microbiol Indones. 2014;8(3):135-9.

13. Haley LD, Callaway CS. Laboratory methods in medical mycology. $4^{\text {th }}$ ed. Atlanta, Ga: U.S. Department of Health, Education and Welfare, Center for Disease Control; 1978.

14. Surja SS, Wijaya M, Padmasutra L, Yolanda $\mathrm{H}$, Joprang FS, Makimian R, et al. Atlas parasitologi kedokteran. $1^{\text {st }}$ ed. Jakarta: Penerbit Universitas Katolik Indonesia Atma Jaya; 2019.

15. Agarwal RK, Gupta S, Mittal G, Khan F, Roy S, Agarwal A. Antifungal susceptibility testing of dermatophytes by agar based disk diffusion method. Int $\mathrm{J}$ Curr Microbiol Appl Sci. 2015;4(3):430-6.

16. de Capriles $\mathrm{CH}$, Mata S, Middelveen M. Preservation of fungi in water (Castellani): 20 years. Mycopathologia. 1989;106(2):73-9.

17. Karabiçak N, Karatuna O, Akyar I. Evaluation of the viabilities and stabilities of pathogenic mold and yeast species using three different preservation methods over a 12-year period along with a review of published reports. Mycopathologia. 2016;181(5-6):415-24.

18. Reggiori F, Klionsky DJ. Autophagic processes in yeast: Mechanism, machinery and regulation. Genetics. 2013;194(2):341-61.

19. Pollack JK, Harris SD, Marten MR. Autophagy in filamentous fungi. Fungal Genet Biol. 2009;46(1):1-8.

20. Hartsell SE. Microbiological process report. Maintenance of cultures under paraffin oil. Appl Microbiol. 1956;4(6):350-5. 